\title{
Body Fat Percentage and Body Mass Index as Predictors of Cadets' Physical Performance
}

\author{
Ioanna Spartali ${ }^{*}$ Havenetidis Kostantinos, Kostoulas Ioannis and Paxinos Thrasivoulos
}

Hellenic Army Academy, Faculty of Physical and Cultural Education, Vari, Athens, Greece

\begin{abstract}
The purpose of this study was twofold: Firstly, to examine the use of Body Mass Index (BMI) and Body Fat (BF \%) measurements in order to monitor the cadets in the Hellenic Army Academy and secondly, to evaluate the aspects that enhance the performance of the cadets in specific physical activities, in order to help them to be more efficient in their duties as officers. More specifically, this study sets out to examine the advantage or disadvantage that cadets, with specific body composition have towards their peers and whether these characteristics can predict their performance in specific tests. Anthropometric measurements (height, body mass, BMI and BF \%) and performance in specific physical tests were assessed for 868 male cadets with an average age of 19.9 1.6 years from all 4 undergraduate classes of the Academy. The results were extracted through odds ratios analysis for the different categories. It was shown that the cadets who belonged to groups with lower BMI and BF \% had an advantage in their performance during the tests. BF \% was presented as a more accurate predictor than BMI and the odds ratios for the tests revealed interesting associations, between the $\mathrm{BF} \%$ of the cadets and their probability to accomplish specific tasks, which may help to enhance performance. In conclusion, it was recommended to use more than one anthropometric component for classification of the cadets and not to depend solely on BMI values, in order to have a more holistic picture of their physical condition and physical activity levels.
\end{abstract}

Keywords: BMI, BF\%, cadets, Hellenic Army Academy, odds ratio, physical activity.

\section{INTRODUCTION}

A common challenge in the developed countries is the accelerating decline in physical activity in everyday life. In adults both poor physical fitness and physical inactivity are associated with morbidity and mortality and most analyses have shown a reduction of at least $50 \%$ in mortality among highly fit people compared with low fit people [1]. Inactive lifestyles, together with easy access to food (including unhealthy fast food), have led to an increase in excessive body weight among people. Health authorities have noted with concern that we may be facing a dramatic increase in the prevalence of lifestyle-related disorders such as diabetes [2], metabolic syndrome [3], arterial hypertension, and osteoarthritis [4] among adults. Moreover, during the last decade, alarming research reports have raised awareness about increasing obesity and fitness deterioration among adolescents [5]. Both overweight and poor physical fitness have been associated with adverse health outcomes at older ages, and a strong relationship has been suggested between body composition and physical fitness.

The relationship between body size and composition and the performance of physically demanding military jobs has been discussed by researchers. It is reasonable to consider that body composition may influence military performance.

\footnotetext{
*Address correspondence to this author at the Hellenic Army Academy, Faculty of Physical and Cultural Education, Vari, Athens, Greece;

Tel: +306977601035; E-mail: yannaspartali@yahoo.com
}

According to Friedler [6], today's soldiers are heavier than before, reflecting both increased muscle and fat components. The high prevalence of overweight and obesity in military recruits and in the general population as a whole necessitates understanding the health effects of body composition and associated morbidity. Several studies, have examined the effect of body mass index (BMI; in $\mathrm{kg} / \mathrm{m}^{2}$ ) and medical status on either the premature discharge from the Army [7], the fitness level of the subjects [8] or the risk of injuries $[9,10]$ in a large cohort of active-duty soldiers. The results agreed that enlistment BMI and medical qualification status play an important role in early discharge and may provide a valuable tool in the development of fitness, nutrition, and injury-prevention interventions.

Harman and Frykman-Scott [11] suggested that lifting and carrying are the most common military tasks: Typical military lifting tasks include loading artillery shells, lifting supplies onto and removing them from trucks, moving construction equipment, and assembling or disassembling heavy equipment. Most lifts involve raising an object from the ground to between waist and shoulder height. Carrying is usually associated with lifting. A soldier is generally expected to lift objects weighing as much as $50 \mathrm{~kg}$ singlehandedly, with heavier objects lifted by more than one individual. In heavy lifting jobs, 38 to $90 \mathrm{~kg}$ objects may be lifted and carried up to 183 meters by a single individual. Packs in excess of $45 \mathrm{~kg}$ and other heavy loads may be lifted and carried for several miles. They found a higher correlation between load carriage performance and lean body mass than between load carriage and percentage of body fat. 
Based on their results, they conclude that it is more important to screen for lean body mass than for body fat.

Higher weight (and fatness) negatively impact endurance performance in two ways: (1) weight appears in the denominator of the $\mathrm{VO}_{2}$ expression greater weight is associated with lower weight-relative $\mathrm{VO}_{2 \max }$; and (2) greater weight increases the energy cost (and required $\mathrm{VO}_{2}$ ) associated with any level of activity. Therefore, the percentage of $\mathrm{VO}_{2 \max }$ required by any level of activity is higher in heavier (and fatter) individuals because energy cost is increased and weight-relative $\mathrm{VO}_{2 \max }$ is reduced. Since a measure of endurance fitness is reflective of both physiological fitness and weight status, BMI adds little to a model for predicting injury that includes fitness.

According to studies conducted at Fort Jackson and Fort Leonard Wood in the 1980s and 1990s [12,13], there are no systematic relationships between injury and BMI or injury and body fat in military recruits. In one study, the highest percentage of injuries was found in the low and high BMI quartiles; in another study there was only slight variability across quartiles; and in a third study the injury rates in the top three quartiles were not significantly different from one another (38 to 42 percent). These patterns were similar for men and women, although the injury rates for women were double the rates for men.

A previous study, within the Hellenic Army Academy conducted by Havenetidis et al. [14], clearly indicates a strong effect of these anthropometric characteristics on the performance of the cadets. However, the current study made an effort to enlighten even deeper the specific topic, by examining more in depth the relation between the BMI of the cadets and their body fat percentage. The relationship between these two variables (BMI and BF) is of high importance for all the military services, since they all have developed specific standards and classify their officers according to them every year. However, due to the large numbers of military personnel that require body composition assessment, all the approaches used have to balance practicality with reliability of the measurement, and that is their biggest limitation.

The body mass index (BMI) has become the standard parameter used to predict body fat when all that is known is the subject's weight and height. Although the limitations of BMI as a predictor of body fat are well recognized [15], it has become widely accepted because of its simplicity. However, the BMI has limitations; it tends to have high specificity, but low and variable sensitivity. Further, the validity of BMI across diverse samples of different age, race, and gender has not been evaluated [16]. The regression relations that are currently used to predict body fat from BMI are based on simple empirical fits to the data, and are assuming that the $\mathrm{BMI}$ and $\mathrm{BF} \%$ are independent of gender and age, which is not always the case [17]. If the classification of the individuals is based solely on their BMI, this is only a moderate predictor of body fat. For this reason body fat percentage was also measured.

The military services demand every year from their members to undertake physical tests and to maintain a specific body composition in order to stay healthy and be able to complete physically demanding tasks. Thus, for this population BMI and body fat examination is essential to determine firstly a classification for their status and secondly to help them, by having this information, to succeed in their everyday activities within the forces. The purpose of the present study was twofold: a) to compare the accuracy of $\mathrm{BMI}$ and $\mathrm{BF} \%$ as indices of cadets' body composition status classification and b) to evaluate these two indices as predictors of cadets' physical fitness level in specific performance activities.

\section{METHODS}

The participants of this study were 868 male cadets, with an average age of $19.9 \pm 1.6$ years, average height $178.5 \pm 6.4$ $\mathrm{cm}$, average weight $77.4 \pm 9.1 \mathrm{~kg}$, the mean BMI was $24.3 \pm 2.4$ and their mean $\mathrm{BF} \%$ was $11.8 \pm 4.4$; and they were equally distributed to the 4 classes of the Academy. These cadets were representing the total of the male cadets of the Academy, so they were not selected out of a group, the whole of the group participated in the study. As far as it concerns their physical activity level, it has to be noted that the Military Academy does not keep any records of the previous athletic experience of the cadets. However, all the candidates need to have a specific physical activity level to enter the academy (they have to pass specific physical activity tests) and after entering the Academy, they all follow a guided physical activity program consisting of 8 hours of exercise per week ( 2 hours per day for 4 days) for all 4 classes in similar activities and their nutrition is also controlled. Therefore, the participants were considered to have similar physical activity level and the observations of this study are explained on this base.

Anthropometric characteristics were measured prior to the tests, more specifically; body weight was measured using commercial scales with an accuracy of 100 gr and with the cadets wearing shorts and t-shirt only. Body height was recorded by tape measure, with each cadet in a standing position and without shoes. The BMI of the cadets was computed by dividing the measured body weight in kilograms by the squared body height in meters [18]. Following the WHO's guidelines [18], BMI under 18.5 was classified as underweight, 18.6-24.9 as normal, 25-29.9 was overweight and over 30 was classified as obese. The anthropometric data in this study, was collected during the exam period of one semester (i.e. within 1 calendar month) and by two specific examiners at all times. One was appointed for weight and height and the other was recording the $\mathrm{BMI}$ and $\mathrm{BF} \%$ of the cadets at all times, in order to assure the reliability of the measurement. Their performance in the tests was recorded by the supervisor of each year (i.e. 4 head examiners) since it was representing their grade in the physical education subject for this specific exam period and these results were submitted by the end of the exam period to be included in the current study.

The bioelectrical impedance analysis (BIA) method was used to measure body fat percentage. In order to decrease the effect of the limitations of this method, since it was the only possible method due to the size of the sample, the lack of time and funds, three steps were followed. Firstly, the model that was used, had tetra polar arrangements by using 8 electrodes and it required the subject to stand on metal footpads in bare feet grasping a pair of electrodes fixed on a 
handle with arms extended in front of the chest. According to bibliography this method is the most accurate from all the BIA methods [19] and a specific model OMRON BF-500 was validated in this study. Secondly, the measurements were performed with the subject having clean hands and bare feet, at the same time of the day and with the same hydration level according to instructions previously given to them. The categories of body fat percentage derived from the American Council of Exercise which are also in agreement with the American Army Standards are:

$\begin{array}{ll}\text { Underweight } & \text { under } 5 \% \\ \text { Normal } & 5 \%-14.9 \% \\ \text { Overweight } & 15 \%-23.9 \\ \text { Obese } & 24 \% \text { and over }\end{array}$

Three databases were used each containing the results of one fitness test, that the cadets undertook as part of their semester examination. The three tests were pull ups, 50 meter freestyle swimming and the obstacle course.

a) The pull ups which measure performance of arm and shoulder-flexor muscles, were started from the lowest position with each subject hanging straight and tightly gripping the horizontal bar. During the movement the arms where flexed until the chin was above the bar. Then the body was lowered to the starting position and this movement was repeated continuously until exhaustion. The result of this test was expressed as the number of pull ups completed.

b) The 50 meters freestyle swimming test, involved the successful completion of one swimming course which was 50 meters in length. The results of this test were recorded as the seconds each cadet needed to complete the course.

c) The obstacle course is a purely military fitness test and it involves a series of challenging physical obstacles an individual or team must overcome usually while being timed. Obstacle course is performed by the $3^{\text {rd }}$ and $4^{\text {th }}$ class cadets only, and includes running, climbing, jumping, crawling and balancing elements with the aim of testing speed and endurance. The length of the obstacle course is $500 \mathrm{~m}$. The track comprises 20 obstacles placed at $10 \mathrm{~m}$ intervals at least. Each lane has a width of $2.50 \mathrm{~m}$. [21]. The form of the course is linear with one turn ( $U$ shape) and the surface was firm. The prepared earth in the landing pits was flat in order to avoid heaped up sand. Lines were marking the start and the end of an obstacle and it was not permitted to touch lane lines, delineating the inner edge of the curve of a lane.

The data bases used, included all the information regarding the actual records of the cadets from the above mentioned tests and the grade that this record was representing for the Academy in a percentage scale with the highest possible score (excellent threshold) being 100\%. Every record or number of repetitions was expressed within this percentage scale, in order for the cadets to receive their exam grades. The excellent threshold for pull ups was represented by 12 repetitions. However, many cadets performed more than 12 , but this was not recorded as there was no higher grade. This was the case for other tests also. Similarly, the excellent threshold for the $50 \mathrm{~m}$ swim was 50 seconds, and 4 minutes and 10 seconds for the obstacle course.

Logistic regression method was used in the current study to predict the odds of being a case based on the predictor (s). The odds were defined as the probability of scoring $100 \%$ in one test divided by the probability of scoring under $100 \%$. The odds ratio was the primary measure of this study in order to compare the probability that cadets with low or high $\mathrm{BF} \%$ had to score $100 \%$ in a test, with the probability that cadets with low or high BMI had to score also $100 \%$ in the same tests. Since the data that was used belonged to a group of people who share some same characteristics (e.g., demographic characteristics) it was also necessary to observe the proportion of people in the group for whom the response variable falls into one category or the other and therefore, chi-square values were also calculated and Fisher's exact test for the exact probability.

\section{RESULTS}

The BMI and BF \% categories could be converted into binomial variables as presented in Table $\mathbf{1}$. It can be seen that when the BMI category is normal or overweight then the $\mathrm{BF} \%$ category will most probably also be normal or overweight. However, only about half of the male subjects categorized according to BMI as overweight or obese are also classified as overweight or obese according to $\mathrm{BF} \%$. BMI may be a reliable indicator to BF only when it concerns normal or underweight subjects.

\section{Pull-ups}

Since the number of pull-ups required by the cadets was 12 , it could be recoded into a dichotomous variable, where an under 12 repetitions attempt is when the subject performed less than 12 pull-ups $(484 / 868,55.8 \%)$ and over 12 repetitions when the subject performed at least 12 pullups $(384 / 868,44.2 \%)$. This means that this test is quite difficult. The cross tabulation of the BMI binomial category with the outcome of the pull-ups task is shown in Table 2. Since it is a $2 \mathrm{X} 2$ contingency Table specific statistical procedures could apply. Firstly through the chi-square value $\left(\chi^{2}=19.5, \mathrm{df}=1\right)$ the Fisher's exact test can be used to calculate the exact probability, which is $p<0.01$. This means that the outcome of the pull-ups task is significantly dependent on the BMI binomial category. Subjects of the overweight or obese BMI category had only 33.9\% probability to achieve over 12 repetitions, while subjects of the normal or underweight BMI category had almost equal chances to achieve under or over 12 pull-ups repetitions.

The odds of the two categories (over or under 12 rep) within the normal or underweight BMI category is $283 / 287=$ 0.983 , while within the overweight or obese BMI category it is only $101 / 197=0.513$. The odds ratio (OR) is equal to $0.983 / 0.513=1.92$ with $95 \%$ confidence intervals $(\mathrm{CI}) 1.43$ 2.56. This means that the odds of the categories in the pullups task is almost double within the normal or underweight BMI category in comparison to the overweight or obese BMI category. Being overweight or obese according to BMI 
Table1. Cross-Tabulation of BMI with BF \% Binomial Categories

\begin{tabular}{|c|c|c|c|}
\hline \multirow{2}{*}{ BMI } & \multicolumn{2}{|c|}{ BF \% } & Total \\
\cline { 2 - 4 } & Normal or Underweight & 38 & Overweight or Obese \\
\hline \hline Normal or underweight & 532 & 150 & 570 \\
\hline Overweight or obese & 148 & 188 & 298 \\
\hline
\end{tabular}

Table 2. Cross-Tabulation of the BMI and BF \% Binomial Categories with the Outcome of the Pull-Ups Task

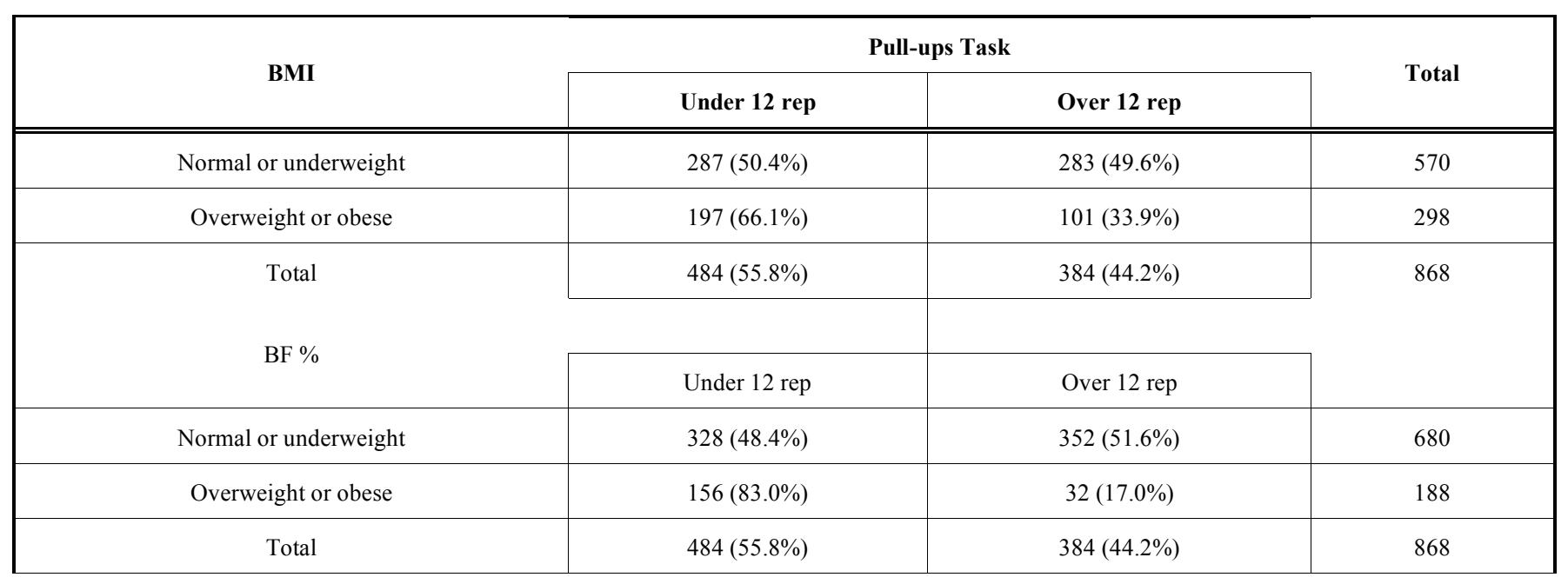

Table 3. Cross-Tabulation of the Combined BF \% and BMI Categories with the Outcome of the $50 \mathrm{~m}$ Swim, $\chi^{2}=17.5, \mathrm{df}=3, \mathrm{p}=0.001$

\begin{tabular}{|c|c|c|c|}
\hline Combined Categories & \multicolumn{2}{|c|}{50 m Swim } & Total \\
\hline $\mathrm{BF} \%$ overweight and BMI normal & $24(63.2 \%)$ & $14(36.8 \%)$ & 38 \\
\hline $\mathrm{BF} \%$ overweight and BMI overweight & $64(42.3 \%)$ & $86(57.7 \%)$ & 150 \\
\hline
\end{tabular}

practically halves the chances of a subject in accomplishing over 12 repetitions of pull-ups.

Table 2 also presents the cross-tabulation of the BF \% binomial category with the outcome of the pull-ups task $\left(\chi^{2}=\right.$ $71.5, \mathrm{df}=1, \mathrm{p}<0.01)$. The chi-square value in this case is obviously much greater than the chi-square value from the relevant BMI category. Moreover the OR is equal to 5.20 with $95 \% \mathrm{CI}=3.46-7.83$. In this case subjects who are normal or underweight have five times more chances to perform over 12 pull-ups than subjects who are overweight or obese. The overweight or obese subjects of the BF category presented high probability (83\%) to perform under 12 repetitions to the pull-ups task. This OR is significantly greater than the OR with the BMI binomial category.

\section{0 m Swim}

The $50 \mathrm{~m}$ swim can be recoded into a dichotomous variable depending on whether the subject completed the distance in swimming under 50 seconds $(548 / 868,63.2 \%)$, or over $50 \mathrm{sec}(319 / 868,36.8 \%)$. As Table 3 shows among subjects with normal BF \% the overall proportion of the under $50 \mathrm{sec}$ performances are $448 / 680$ (65.9\%), which is 
Table 4. Cross-Tabulation of the Outcome of the Pull-Ups Task with the Outcome of the 50m Swim Task

\begin{tabular}{|c|c|c|c|}
\hline \multirow{2}{*}{ Pull-ups } & \multicolumn{2}{|c|}{ 50 m swim } & Under 50sec \\
\cline { 2 - 4 } & Over 50sec & $274(56.6 \%)$ & 484 \\
\hline \hline Under 12 rep & $210(43.4 \%)$ & $275(71.6 \%)$ & 384 \\
\hline Over 12 rep & $109(28.4 \%)$ & $549(63.2 \%)$ & 868 \\
\hline Total & $319(36.8 \%)$ & & 401 \\
\hline
\end{tabular}

$\chi^{2}=20.7 \mathrm{df}=1, \mathrm{p}<0.01, \mathrm{OR}=1.92,95 \% \mathrm{CI}=1.45-2.57$.

Table 5. Cross-Tabulation of the BMI and BF \% Binomial Categories with the Outcome of the Obstacle Course Task

\begin{tabular}{|c|c|c|c|}
\hline \multirow{2}{*}{ BMI } & \multicolumn{2}{|c|}{ Obstacle Course Task } & \multirow{2}{*}{ Total } \\
\cline { 2 - 4 } & Over 250 s & $224(78.3 \%)$ & 286 \\
\hline \hline Normal or underweight & $62(21.7 \%)$ & $94(61.0 \%)$ & 154 \\
\hline Overweight or obese & $60(39.0 \%)$ & $318(72.3 \%)$ & 440 \\
\hline Total & $122(27.7 \%)$ & Under $250 \mathrm{~s}$ \\
\hline BF $\%$ & & $279(77.9 \%)$ & 358 \\
\hline Normal or underweight & Over $250 \mathrm{~s}$ & $39(46.9 \%)$ \\
\hline Overweight or obese & $79(22.1 \%)$ & $318(72.3 \%)$ \\
\hline Total & $43(53.1 \%)$ & 440 \\
\hline
\end{tabular}

BMI binomial category: $\chi^{2}=14.9, \mathrm{df}=1, \mathrm{p}<0.01, \mathrm{OR}=2.3,95 \% \mathrm{CI}=1.5-3.5$

$\mathrm{BF} \%$ binomial category: $\chi^{2}=31.7, \mathrm{df}=1, \mathrm{p}<0.01, \mathrm{OR}=4.0,95 \% \mathrm{CI}=2.4-6.6$

significantly higher than among subjects who are overweight according to $\mathrm{BF} \%(100 / 188,53.5 \%)$. The chi-square is equal to 9.7 with one degree of freedom yielding a $p$ value with the Fisher's exact test equal to 0.002 . Correspondingly the odds ratio is 1.68 with 95\% CI 1.21-2.33. However, within the overweight BF \% category an overweight BMI seems to exert a beneficiary effect towards the under $50 \mathrm{sec}$ completion of the task, or, put otherwise, a normal BMI seems to exert a detrimental effect towards the completion of the task, lowering the proportion of the under $50 \mathrm{sec}$ completions to $36.8 \%$.

Finally, as Table 4 presents, subjects who are performing well in the pull-ups task are more likely to perform well in the $50 \mathrm{~m}$ swim task.

\section{Obstacle Course}

There were 440 male cadets of the $3^{\text {rd }}$ and $4^{\text {th }}$ class performing the obstacle course test. The cut-off time for an excellent completion of the obstacle course run was 4 minutes and 10 seconds, where $318 / 440$ (72.3\%) of the subjects completed the test under $4 \mathrm{~min}$ and $10 \mathrm{~s}$ and the remaining 122/440 (27.3\%) were slower. Table 5 display the cross-tabulation of $\mathrm{BMI}$ and $\mathrm{BF} \%$ binomial categories respectively with the outcome of the obstacle course task. The values of the odds ratio in the second case $(\mathrm{OR}=4.0)$ are significantly greater than in the first case $(\mathrm{OR}=2.3)$. It is obvious from the results that the Normal or underweight subjects of both BMI and BF categories performed much better in this task.

Combining the data displayed in Table 5 it can be seen that within each $\mathrm{BF} \%$ binomial category BMI does not have a significant effect on the outcome of the obstacle course run. Conversely, within each BMI binomial category, especially within the overweight or obese category, BF \% has a significant negative effect on the obstacle course run.

\section{DISCUSSION}

The participants of this study presented differences in their $\mathrm{BF} \%$ and BMI from the standard classification, by having some of them presented as overweight for the BMI classification but were normal for the BF \% classification and vice versa. Thus, some of the cadets are being misclassified either based on their BMI or their BF \% outcomes. It has to be noted that most of the misclassifyication is due to BMI and not $\mathrm{BF} \%$. This can be explained from the nature of these two measurements. $\mathrm{BF} \%$ is more specific than BMI in its nature because it involves a particular body composite, whereas BMI is a crude measurement which includes more than one body composite. This means that, while BMI and BF \% are highly correlated, they also seem to incorporate different somatometric characteristics which may, in conjunction or independently, influence performance on athletic tasks. However, the effect of BF \% appeared to be the stronger of the two. In a similar 
study conducted with college students [20], where the aim was to associate physical activity to $\mathrm{BF} \%$ and body composition, there was a correlation between the highest activity group and their $\mathrm{BF} \%$, which was not reflected through the BMI measurements.

The principle finding of the study was an association between body composition and performance in specific tests in young men. In the current study, there were differences between the groups of the cadets and as it was expected the cadets who were in the normal- underweight groups performed better than the cadets who were in the overweight - obese group for both classifications (BMI and BF \%). The overall results presented $\mathrm{BF} \%$ as a better predictor than $\mathrm{BMI}$ of performance in these specific tests. This was obvious through a series of tests that were performed, but more obviously through the odds ratios. In a study by Stevens et al. [22], the opposite prediction was tested in children, how the physical activity level could predict the body composition and the results indicated that BMI was not associated with physical activity in the normal-weight group, whereas $\mathrm{BF} \%$ was associated with the physical activity levels of the subjects.

The fact that body fat percentage emerged as the strongest predictor of running performance and muscle strength also seems to imply that an increase in the proportion of fat might explain the decrease noted in performance. However, considering that most army academies are based on voluntary young healthy mostly male students, strongly selected in regard to physical fitness, this sample does not represent an entire population of our country. Therefore, comparison between these results should be made with caution. Our findings support the role of body fat mass and body fat percentage as the primary markers of poorer physical performance and this comes in agreement with a similar study conducted by Matiila et al. [5] in Finland.

Finally, a limitation of this study was that the participants were only males. This happened due to two reasons. Firstly, the male cadets were numerically a bigger sample and secondly, due to the fact that the device that we used to measure their $\mathrm{BF} \%$ was reported to be more accurate for male subjects than for female [23]. The main challenge, however, comes in setting appropriate fat standards to support the full range of Army requirements [24].

\section{CONCLUSION}

From the present study it was evident that the cadets who belonged to groups with lower BMI and BF \% had an advantage in their performance during the tests. BF \% was shown as a more accurate predictor than BMI and the odds ratios for the tests revealed interesting associations, which may help to enhance performance. In conclusion, it is recommended to use more than one anthropometric component for classification of the cadets and not to depend solely on BMI values, in order to have a more holistic picture of their physical condition and physical activity levels. We thus, suggest that future studies of body fat ('adiposity') should be formulated rather than rely solely on BMI cut-points of obesity. The percentile values estimated from the present study could be used as the baseline data for the formulation of the standards for these cadets. In this study female cadets did not participate, however, the full integration of women into the military forces, dictates the formation of gender appropriate standards. Also, further work is required to compare the usefulness of percent $\mathrm{BF} \%$ cut-offs with that of BMI classifications of overweight and obesity in predicting increased metabolic and injury risk.

\section{CONFLICT OF INTEREST}

The authors confirm that this article content has no conflicts of interest.

\section{ACKNOWLEDGEMENTS}

None declared.

\section{REFERENCES}

[1] Bovet P, Auguste R, Burdette H. Strong inverse association between physical fitness and overweight in adolescents: a large school-based survey. Int J Behav Nutr Phys Act 2007; 4: 24.

[2] Santilla M, Kyrolainen H, Vasankari T, et al. Physical fitness profiles in young Finnish men during the years 1975-2004. Med Sci Sports Exerc 2006; 38: 1990-4.

[3] Mikkola IS, Keinanen-Kiukaanniemi M, Laakso T, et al. Metabolic syndrome in connection with BMI in young Finnish male adults. Diabetes Res Clin Pr 2007; 76: 404-9.

[4] Janssen I, Mark AE. Separate and combined influence of body mass index and waist circumference on arthritis and knee osteoarthritis. Int J Obes (Lond) 2006; 30: 1223-8.

[5] Mattila V, Tallroth K, Marttinen M, Pihlajamäki H. Body Composition by DEXA and Its Association with Physical Fitness in 140 Conscripts. Med Sci Sports Exerc 2007; 39(12): 2242-7.

[6] Fiedler ER, Oltmanss TF, Turkheimer E. Traits associated with personality disorders and adjustment to military life: Predictive validity of self and peer reports. Mil Med 2004; 169: 207-11.

[7] Packnett ER, Niebuhr DW, Bedno SA, Cowan DN. Body mass index, medical qualification status, and discharge during the first year of US Army service. Am J Clin Nutr 2011; 1: ajcn.007070

[8] Riley DJ, Wingard D, Morton D, et al. Use of self -assessed fitness and exercise parameters to predict objective fitness. Med Sci Sport Exerc 2005; 37: 827-31.

[9] Finestone A, Milgrom C, Evans R, Yanovich R, Constantini N, Moran DS. Overuse injuries in female infantry recruits during lowintensity basic training. Med Sci Sport Exerc 2008: 62: 630-5.

[10] Jones BH, Darakjy S, Knapik FF. Aerobic fitness, body mass index and risk of injury during Army basic combat training. Med Sci Sport Exerc 2004; 36: S308.

[11] Harman EA, Frykman-Scott PN . The relationship of body size and composition to the performance of physically demanding military tasks. In: Marriott BM , Grumstrup-Scott J, Eds. Institute of Medicine, Body composition and physical performance: Applications for the military services, Committee on Military Nutrition Research. Washington, DC: National Academy Press 1992: pp. 105-18.

[12] Jones B, Bovee MW, Harris JM III, Cowan DN. Intrinsic risk factors for exercise-related injuries among male and female army trainees. Am J Sports Med 1993; 21: 705-10.

[13] Jones BH, Bovee MW, Knapik JJ. Associations among body composition, physical fitness, and injury in men and women army trainees. In: Marriott BM, Grumstrup-Scott J, Eds. Institute of Medicine, Body composition and physical performance: Applications for the military services, Committee on Military Nutrition Research. Washington, DC: National Academy Press 1992: pp. 141-73.

[14] Havenetidis K, Kardaris D, Paxinos T. Relationship between military physical fitness tests and selected anthropometric measures. Halkidiki, GREECE: Proceedings of the 11th International Congress of Sport Kinetics 2009.

[15] Prentice AM, Jebb SA. Beyond body mass index. Obes Rev 2001; 2(3): 141-7. 
[16] Sood A, Sundararaj P, Sharma S, Kurpad A, Muthayya S. BMI and Body Fat Percent: Affluent Adolescent Girls in Bangalore City. Indian Pediatrics 2007; 44: 587-91.

[17] Jackson AS, Stanford PR, Gagnon J, et al. The effect of sex, age and race on estimating percentage body fat from body mass index: The Heritage Family Study. Int J Obes 2002; 26: 789-96.

[18] Global Health Observatory. Mean Body Mass Index. World Health Organisation (WHO). Available from: http://www.who.int/gh$\mathrm{o} / \mathrm{ncd} /$ risk factors/bmi text/en/\#

[19] Bosy-Westphal A, Later W, Hitze B, et al. Accuracy of Bioelectrical Impedance consumer devices for the measurement of body composition in comparison to whole body magnetic resonance imaging and dual X-Ray absorptiometry. Obes Facts $2008 ; 1: 319-24$

[20] Zanovec M, Lakkakula AP, Johnson LG, Tuuri G. Physical Activity is Associated with Percent Body Fat and Body
Composition but not BMI in White and Black College Students. Int J Exerc Sci 2009; 2(3). Available from: http://digitalcommons.wku.edu/ijes/vol2/iss $3 / 3$.

[21] International Military Sports Council. Military Pentathlon: Contes regulations 2003; www.military-pentathlon.org.

[22] Stevens J, Suchindran C, Ring K, et al. Physical Activity as a predictor of body composition in American Indian children. Obes Res 2004; 12(12):1974-80.

[23] Pribyl MI, Smith JD, Grimes GR. Accuracy of the Omron HBF500 body composition monitor inn male and female college students. Int $\mathbf{J}$ Exerc Sci 2011; 4(2). Available from: http://digitalcommons.wku.edu/ijes/vol4/iss $2 / 2$

[24] Friedl KE. Body composition and military performance-many things to many people. J Strength Cond Res 2012; 26: 87-100.

(c) Spartali et al.; Licensee Bentham Open.

This is an open access article licensed under the terms of the Creative Commons Attribution Non-Commercial License (http://creativecommons.org/licenses/ by-nc/3.0/) which permits unrestricted, non-commercial use, distribution and reproduction in any medium, provided the work is properly cited. 